Article

\title{
Surface Characterization and Tribological Behavior of Graphene-Reinforced Cellulose Composites Prepared by Large-Area Spray Coating on Flexible Substrate
}

\author{
Shih-Chen Shi ${ }^{1, *(\mathbb{O})}$, Chih-Chia Wang ${ }^{2,3}$, Yung-Chen Cheng ${ }^{4}$ and Yue-Feng Lin ${ }^{5}$ \\ 1 Department of Mechanical Engineering, National Cheng Kung University, Tainan 70101, Taiwan \\ 2 Department of Chemical and Materials Engineering, Chung Cheng Institute of Technology, \\ National Defense University, Taoyuan 33509, Taiwan; ccith06001@ndu.edu.tw \\ 3 System Engineering and Technology Program, National Chiao Tung University, Hsinchu 30010, Taiwan \\ 4 Department of Materials Science, National University of Tainan, Tainan 70005, Taiwan; \\ chengyc@mail.nutn.edu.tw \\ 5 Department of Mechanical Engineering, National Chin-Yi University of Technology, Taichung 41170, Taiwan; \\ yflin@ncut.edu.tw \\ * Correspondence: scshi@mail.ncku.edu.tw; Tel.: +886-6-2757575 (ext. 62176); Fax: +886-6-2352973
}

Received: 30 October 2020; Accepted: 30 November 2020; Published: 1 December 2020

\begin{abstract}
A large-area spray coating process is introduced to efficiently apply a graphene/Cu/cellulose composite on a flexible glass substrate. The dispersion characteristics of nano-additives are measured and the Tyndall effect observed. The characteristics of the composite coating such as the film thickness, surface roughness, water contact angle, and lubricating characteristics are measured. The tribological properties of the composite coating are measured using a ball-on-disk. The wear width of the abrasive parts, as well as the wear and friction coefficient of the grinding balls, are investigated. Adding graphene/Cu helps to improve the anti-wear ability of cellulose. The transfer layer was observed using the Raman spectroscopy and mapping technology. Finally, the lubricating mechanism is discussed, and the wear mechanism is proposed. Nanoparticles existed in the wear track as the third-body particles and improved the load capacity of the composites. The wear mechanism of the composites is discussed in terms of the worn surfaces and the analysis of the transfer film with the third-body approach.
\end{abstract}

Keywords: tribology; wear; graphene; cellulose; large area; spray coating; flexible substrate

\section{Introduction}

Consumer electronics such as smartwatches, smartphones, head-up displays, and computer screens, as well as automotive electronics and flexible devices, have attracted much attention in the last few decades, increasing the demand for large area and flexible substrates. Consequently, the demand for protecting the surface of substrates also increased. Hence, the substrates are coated with different materials to prevent any damage. The efficient use of electronic products with an increased service life of electric films is a topic worth exploring. However, there are not many studies on the preparation of protective coatings on large-area glass substrates. In this study, a protective layer was prepared by spraying technology on a flexible substrate and its lubricating characteristics were studied.

Spin and spray coatings are widely used in large-area coating processes. In recent years, spin coating has been used to prepare conductive coatings, such as solar cell structure [1,2], transparent conductive oxide [3,4], and conductive layers for other applications [5]. Spray coating has also been widely used to prepare materials such as perovskite solar cells [6], transparent conductive electrodes [7], compact layers [8], nanocomposites [9], and highly conducting metal layers [10]. However, there are few studies on the use of spin and spray coatings for large-area polymer lubricating protection coatings. 
The preparation and stability of the slurry significantly influence the characteristics of spray coating; the dispersion of additives in the slurry is particularly impacted [11-13]. In recent years, the awareness of environmental protection has increased the use of biopolymer materials, such as cellulose [14-16], chitosan $[17,18]$, and gelatin $[19,20]$. Furthermore, the various engineering applications of these materials, such as biopolymer anti-corrosion coatings [21-24], self-repairing layers [25-27], anti-wear layers [28,29], and friction-reduction layers [30,31], have received significant attention. In composite materials, the size, appearance, and degree of aggregation of additives significantly influence their properties, such as wear characteristics [32,33], electrical conductivity [34,35], thermal conduction [36,37], and mechanical strength $[38,39]$.

In this study, nano-graphene is used as an additive to explore the influence of its dispersion on the properties of nano-graphene/copper/cellulose composite coatings (NGCC). Spraying is used to prepare the composite coating. Importantly, the overall target is a $20 \%$ reduction in friction and wear. Material and wear properties of the composite coating under large-area manufacturing are discussed, and a tribology protection material suitable for practical applications in the conductive layer of the large-area screen surface is developed.

\section{Materials and Methods}

\subsection{Slurry Preparation and Characteristic Analysis}

$\mathrm{Cu}$ nanoparticles with an average size of $137 \mathrm{~nm}$ were obtained from Yi-Mei Company (Taipei, Taiwan). Graphene is prepared on the $\mathrm{Cu}$ nanoparticles via chemical vapor deposition $\left(600{ }^{\circ} \mathrm{C}\right.$ for $60 \mathrm{~min}$ ) to give rise to the graphene/Cu nanoparticles [16]. Hydroxypropyl methylcellulose (HPMC) solution is prepared by mixing $5 \mathrm{~g}$ of HPMC (606, Shin-Etsu, Osaka, Japan) powder in $100 \mathrm{~g}$ of deionized water. The nanoparticle suspension is prepared by adding $0.02-0.1 \mathrm{~g}$ of the graphene/Cu nanoparticles into $10 \mathrm{~g}$ of ethanol. Slurry is prepared by mixing $10 \mathrm{~g}$ HPMC solution and $10 \mathrm{~g}$ nanoparticle suspension, then stir at $400 \mathrm{rpm}$ on an electromagnetic heating stirrer for $10 \mathrm{~min}$ [13]. The hydrodynamic diameter of the suspension is measured with a dynamic light scattering instrument (Dynamic Light Scattering, DLS, Delsa Nano C, Beckman Coulter, Brea, CA, USA). The Tyndall effect is observed by filling the nanoparticle suspension into a glass bottle, using a laser pointer to illuminate the glass bottle, and then recording the laser light path.

\subsection{Large-Area Spraying and Flexible Glass Substrate}

Spraying is performed using a high-efficiency oil-free air compressor (Model 30L, Japan Star, Kaohsiung, Taiwan), operated at 8-10 bar, and a spraying nozzle (W71, Anest Iwata, Yokohama, Japan), which is mounted on a programmable robot arm. The distance between the nozzle and glass substrate is fixed to $5 \mathrm{~cm}$. Ultra-thin borosilicate glass (Corning, New York, NY, USA) $0.1 \mathrm{~mm}$ thick and $100 \mathrm{~mm}$ $\times 100 \mathrm{~mm}$ in size is used as the flexible substrate.

\subsection{Material Property Analysis of Composite Coating}

The thickness and surface roughness $(R a)$ of the film are measured by a 3D laser scanning microscope (VK9700, Keyence, Osaka, Japan). The surface energy is recorded by a contact angle analyzer (First Ten Angstroms/FTA-1000B, Portsmouth, UK). The transfer layer and distribution of nano-graphene in the composite coating are observed by Raman spectroscopy (MRID, ProTrusTech Co., Ltd., Tainan, Taiwan) and Raman mapping.

\subsection{Tribological Behavior of Composite Coating}

The tribological behavior is recorded using a ball-on-disk tribometer. Specifically, the tester model POD-FM406-10NT (Fu Li Fong Precision Machine, Kaohsiung, Taiwan) manufactured in Taiwan is used, under a load of $2 \mathrm{~N}$, disk speed of $0.03 \mathrm{~m} / \mathrm{s}$, and friction distances of 10,15, and $20 \mathrm{~m}$. The upper test piece is a $6.31 \mathrm{~mm}$ diameter chrome steel ball (52,100 steel), and the lower test piece is a composite 
coated glass substrate. The wear test is performed in a dry environment at $25{ }^{\circ} \mathrm{C}$ and relative humidity of $70 \%$. The friction coefficient of the coating is monitored and recorded in real time by sensors located on the testing machine, and the wear width is measured using an ultra-high-resolution scanning electron microscope (UHRFE-SEM, AURIGA, Carl Zeiss AG, Jena, Germany). The final experimental results obtained are the average of three sets of experimental data.

\subsection{Third-Body Theory}

The third-body theory is used to describe the interaction and different motion states of the wear parts, friction interfaces, abrasive particles, and lubricants during the wear process under dry friction conditions. Third-body, in terms of materials, can be defined as the change in the composition of the interface material during the wear process $[40,41]$. Velocity accommodation mechanism refers to the location and motion state of wear as sites (S) and modes (M). S1 and S5 are called the first-bodies, which represent two counter-wear parts; S3 represents natural wear debris generated by abrasion or lubricant additive; S2 and S4 are the interface layers between S1-S3 and S5-S3. Mode represents the mode of velocity accommodation. M1 to M4 represent elastic deformation, normal breaking/rupture, shearing/sliding, and rolling mechanism, respectively [42].

\section{Results and Discussion}

\subsection{Dispersion Characteristics of Slurry}

The fluid dynamics of nano-graphene/Cu slurry measured by DLS is shown in Figure 1. As shown in this figure, the diameter of DLS is directly proportional to the additive concentration, which means that when the number of nano-additives in the suspension increases, the particles tend to aggregate and form larger-sized particles.

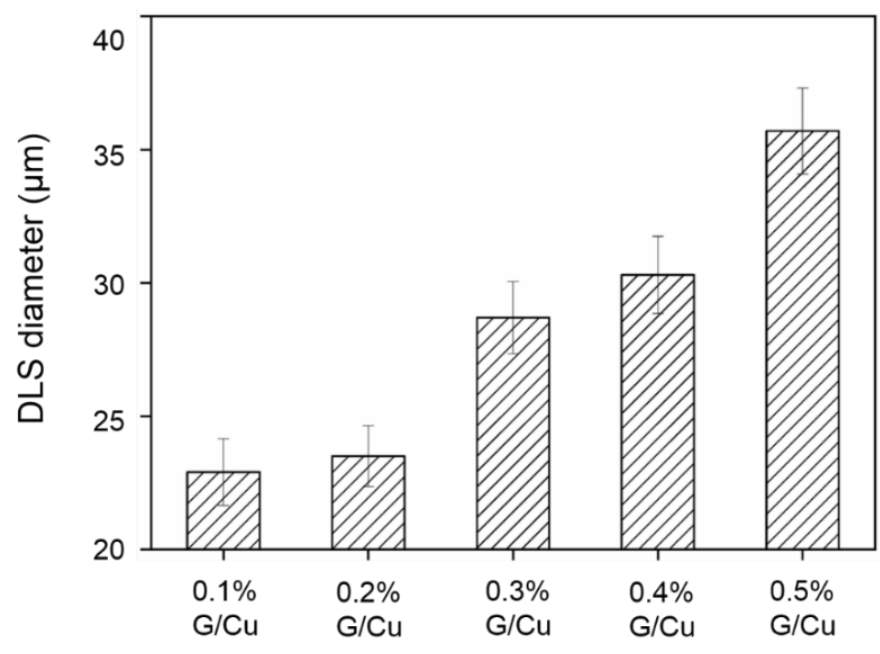

Figure 1. DLS diameter of nano-graphene/Cu slurry.

The result of the Tyndall effect is shown in Figure 2. The HPMC solution itself exhibits the Tyndall effect. However, as the nano-graphene/copper content increases, the aggregation of particles causes uneven dispersion, and the scattering of light gradually turns into reflection. The Tyndall effect is almost negligible for concentrations higher than $0.2 \mathrm{wt} \%$. Figures 1 and 2 directly indicate that when the concentration of nano-additives is high, they will tend to aggregate and form larger particles, causing precipitation and laser-light penetration. 


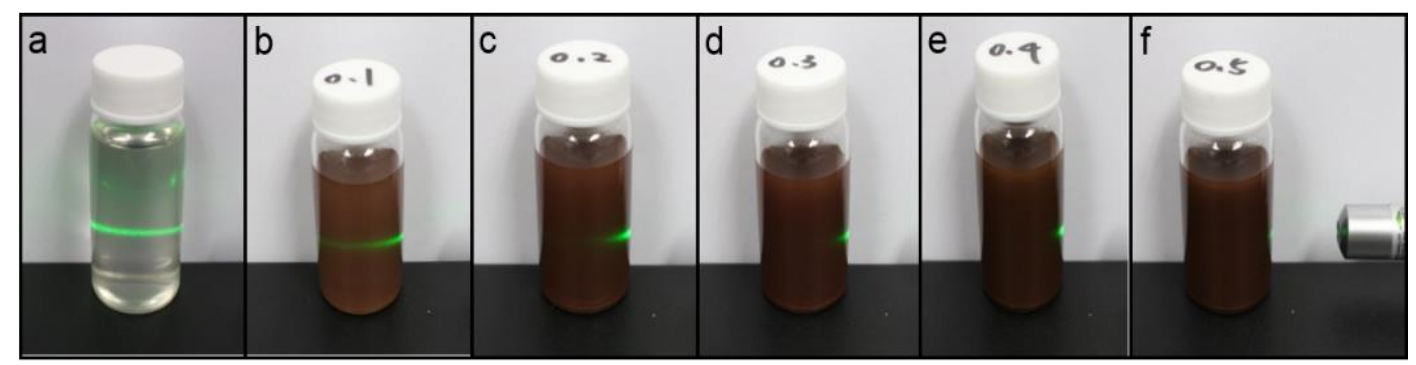

Figure 2. Tyndall effect of (a) HPMC solution, (b) $0.1 \%$ G/Cu slurry, (c) $0.2 \%$ G/Cu slurry, (d) 0.3\% G/Cu slurry, (e) $0.4 \% \mathrm{G} / \mathrm{Cu}$ slurry, and (f) $0.5 \% \mathrm{G} / \mathrm{Cu}$ slurry.

\subsection{Properties of Slurry and NGCC}

The thickness of composite film with various additive amounts is shown in Figure 3. The consistency of the composite material thickness can be retained at different additive amounts, indicating the good stability of the large-area spraying process, and no precipitation occurring in the slurry over time. The surface roughness $\left(R_{\mathrm{a}}\right)$ of the film is shown in Figure $4 \mathrm{a}$. The surface roughness of the composite coating increases slightly with the increase in additives. The appearance of particles is shown in Figure $4 \mathrm{~b}-\mathrm{f}$; the particle size tends to increase with increasing additives. This phenomenon indicates that nano-graphene/ $\mathrm{Cu}$ aggregates at higher concentrations. The observations of the surface morphology are consistent with the result of the Tyndall effect shown in Figure 2.

According to previous studies, a hydrophobic surface can reduce the polarity and capillary force, thereby reducing the adhesion and friction of the surface [43]. The water contact angles of the composite coating are shown in Figure 5. Increasing the $\mathrm{G} / \mathrm{Cu}$ additives increases the hydrophobicity of the composite coating surface. This result represents that the quality of nano-graphene as an additive is remarkable, and after combining it with the HPMC matrix, high surface energy can be obtained. The hydrophobic nature of the composite coating contributes to the lubrication performance.

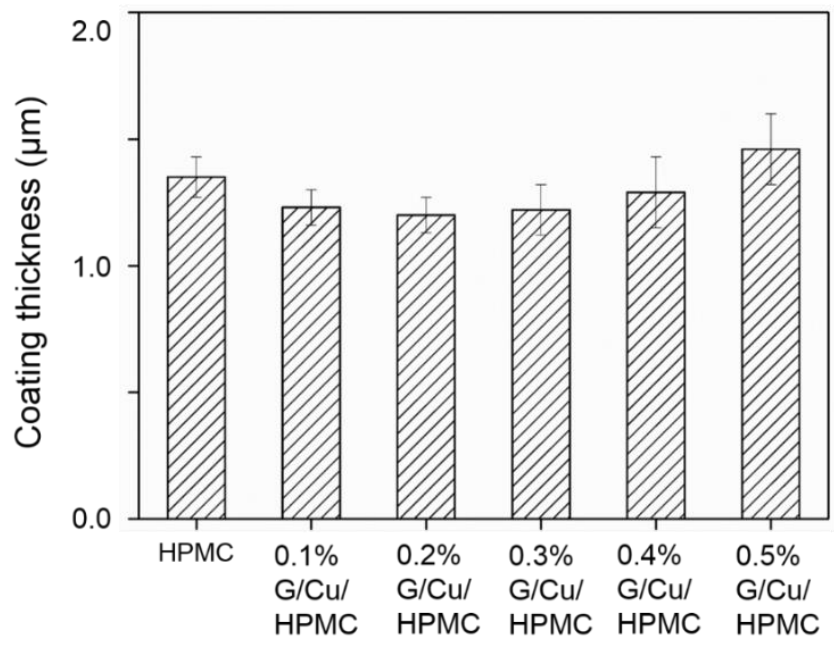

Figure 3. Thickness of composite coating with different amounts of nano-graphene/copper additive. 


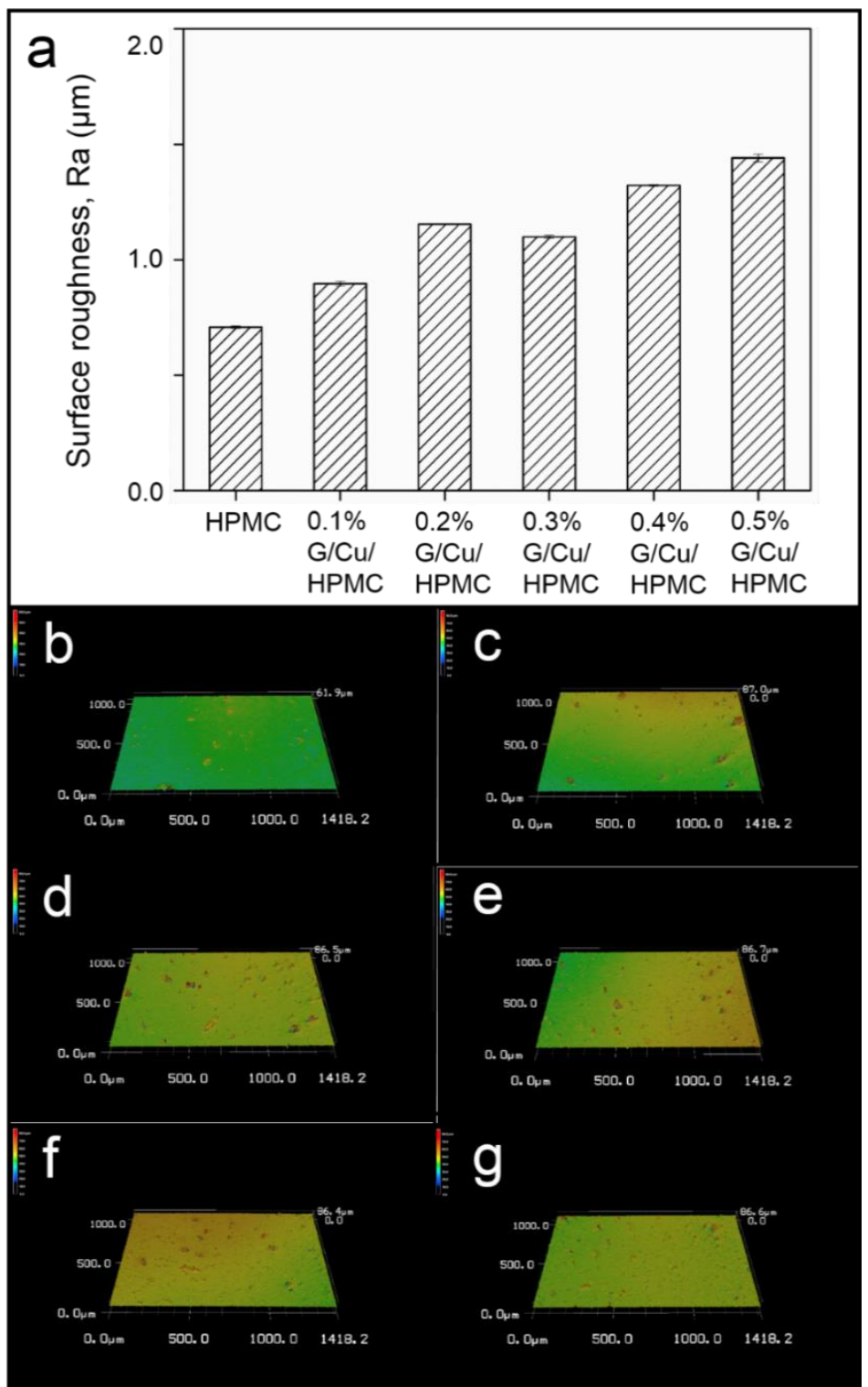

Figure 4. (a) Surface roughness $\left(R_{\mathrm{a}}\right)$ of composite film; surface morphology of composite coating with (b) no additive, (c) $0.1 \% \mathrm{G} / \mathrm{Cu}$, (d) $0.2 \% \mathrm{G} / \mathrm{Cu}$, (e) $0.3 \% \mathrm{G} / \mathrm{Cu}$, (f) $0.4 \% \mathrm{G} / \mathrm{Cu}$, and (g) $0.5 \% \mathrm{G} / \mathrm{Cu}$.

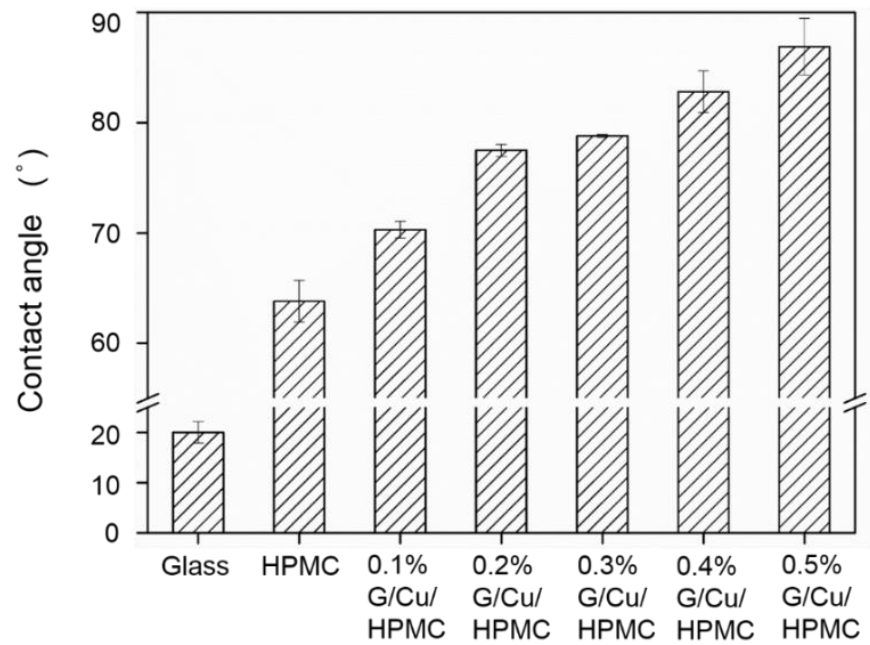

Figure 5. Water contact angle of composite coatings. 


\subsection{Tribological Performance of Composite Coating}

Figure 6 shows the surface morphology of $0.3 \%$ NGCC at different wear distances. To measure the wear width, the diameter of the red circle shown in Figure 6 is measured. The longer the wear distance, the broader the wear width; meanwhile, obvious transfer layers can be observed in the wear area (as indicated by the white arrow).

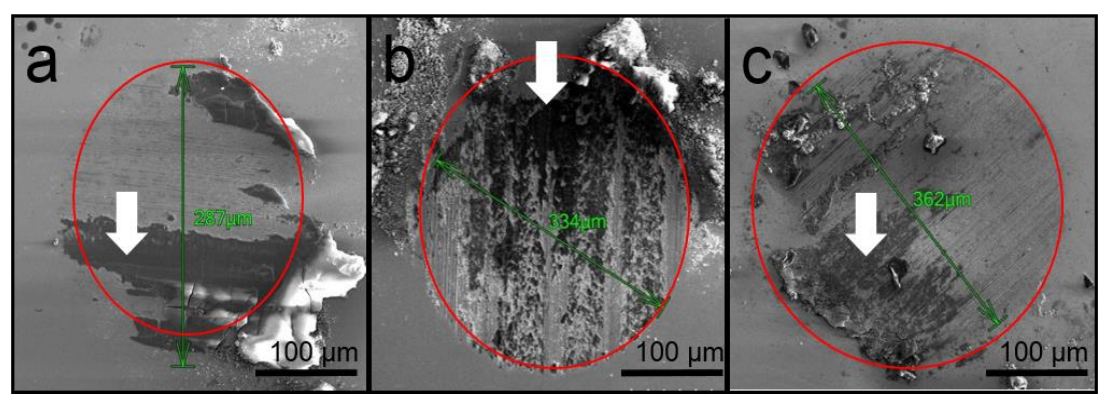

Figure 6. Wear width and transfer layer of $0.3 \%$ NGCC at the wear distance of (a) 10, (b) 15, and (c) $20 \mathrm{~m}$.

The wear characteristics of NGCC with various additive concentrations are shown in Figure 7. When nano-graphene is added to the HPMC matrix as an additive, the wear can be effectively reduced. Generally, the excess additive does not help much in wear-reduction. This phenomenon shows that graphene is an effective anti-wear medium, which appears between two wear parts when the wear occurs. A small amount of graphene can provide excellent anti-wear properties. The result of the average coefficient of friction is shown in Figure $7 b$, which is similar to Figure $7 a$, illustrating the excellent lubricating behavior of graphene.
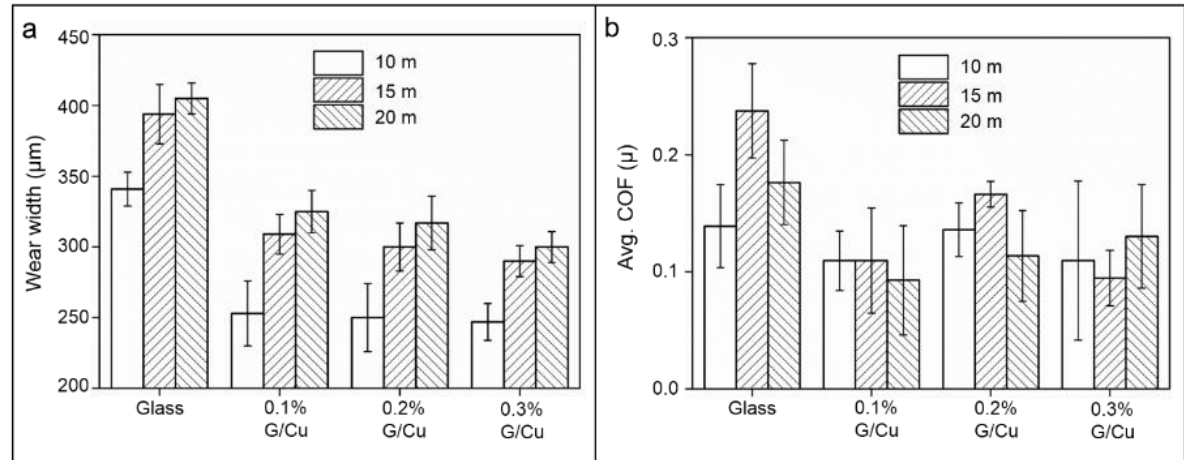

Figure 7. (a) Wear width and (b) average friction coefficient of NGCC.

The Raman spectroscopy analysis of the upper specimen (chromium steel ball) and the wear scar of the coating are shown in Figure 8a,b, respectively. The two dashed lines in the figures represent the D and $G$ peaks of graphite at 1346 and $1575 \mathrm{~cm}^{-1}$ respectively. The figures show the signal variation with various NGCCs under different wear distances. Graphene is observed in either the chrome steel ball or the wear scar. It represents graphene transfer to the counter-grinding part (chrome steel ball) during the wear process. Further evidence of the transfer layer is shown in Figure 9 by the images obtained via Raman mapping. The bright spots represent the presence of graphene. Figure $9 a, c$ are photos captured with an optical microscope (OM), and Figure 9b,d are Raman mapping images. The Raman mapping results reveal that a considerable amount of graphene is on the surface of the chromium steel ball, which means that graphene is transferred from the coating to the surface of the counter-wear part as a transfer layer. 


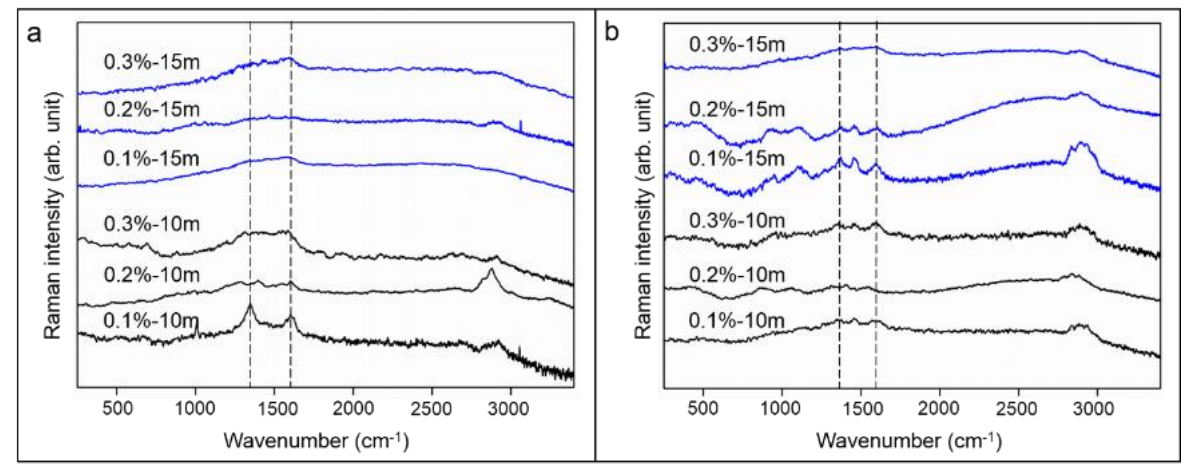

Figure 8. Raman signal on (a) the surface of chrome steel ball and (b) in the wear scar.

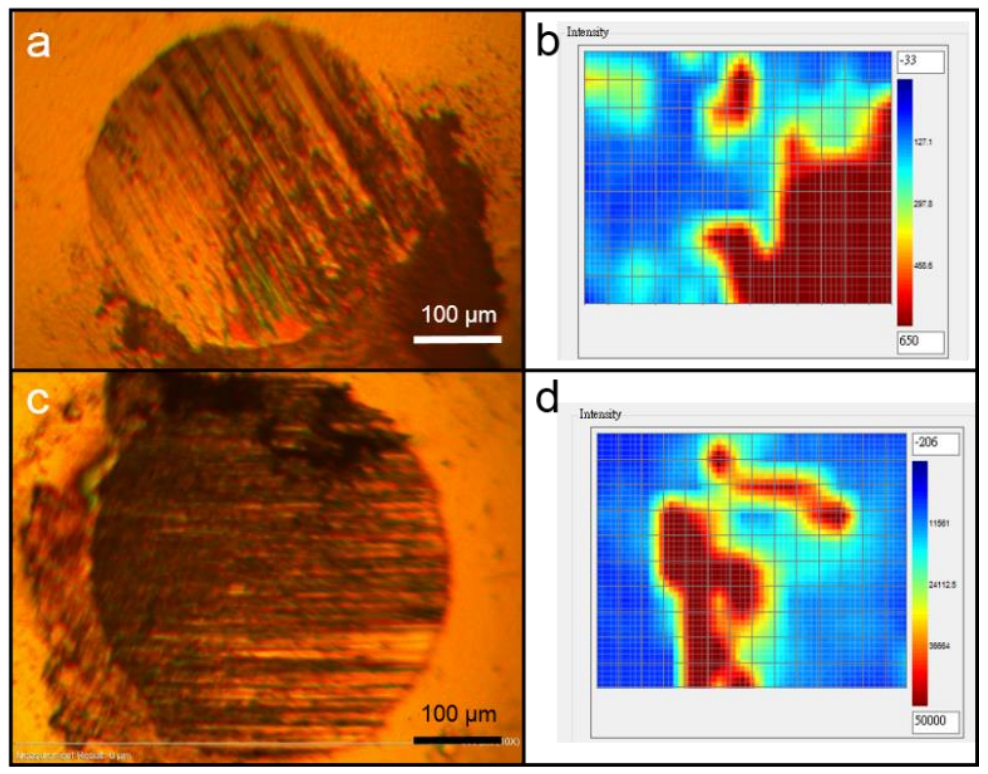

Figure 9. (a) OM image of chromium steel ball surface at a wear distance of $10 \mathrm{~m}$; (b) Raman mapping image of (a); (c) OM image of chromium steel ball surface at a wear distance of $15 \mathrm{~m}$; (d) Raman mapping image of (c).

Figure 10 shows the results of SEM, OM, and Raman mapping on the surface of the wear scar. In Figure 10a, a high contrast area is observed in the wear scar. Further analysis by OM and Raman mapping reveals the presence of graphene. This signifies that the nano-graphene additives remain on the coating surface even after $15 \mathrm{~m}$ of wear. When abrasion occurs, a part of graphene is transferred to the upper chrome steel ball forming a transfer layer, and another part of it remains on the coating to reduce wear and friction. This serves as key evidence that the graphene transfer layer is observed on the surface of the grinding ball (S1). As per the observations made in previous studies, materials with a layered structure, such as $\mathrm{MoS}_{2}$, and graphene tended to form a transfer layer when wear occurred. Meanwhile, the shear/sliding (M3) velocity accommodation mode was commonly observed in layered materials during abrasion. Therefore, only a very small quantity of additives is required to achieve wear and friction reduction. In this study, residual graphene can be observed on the surface of the coating (S5), indicating that the M3 velocity accommodation mode can be supported by graphene during the wear process. 


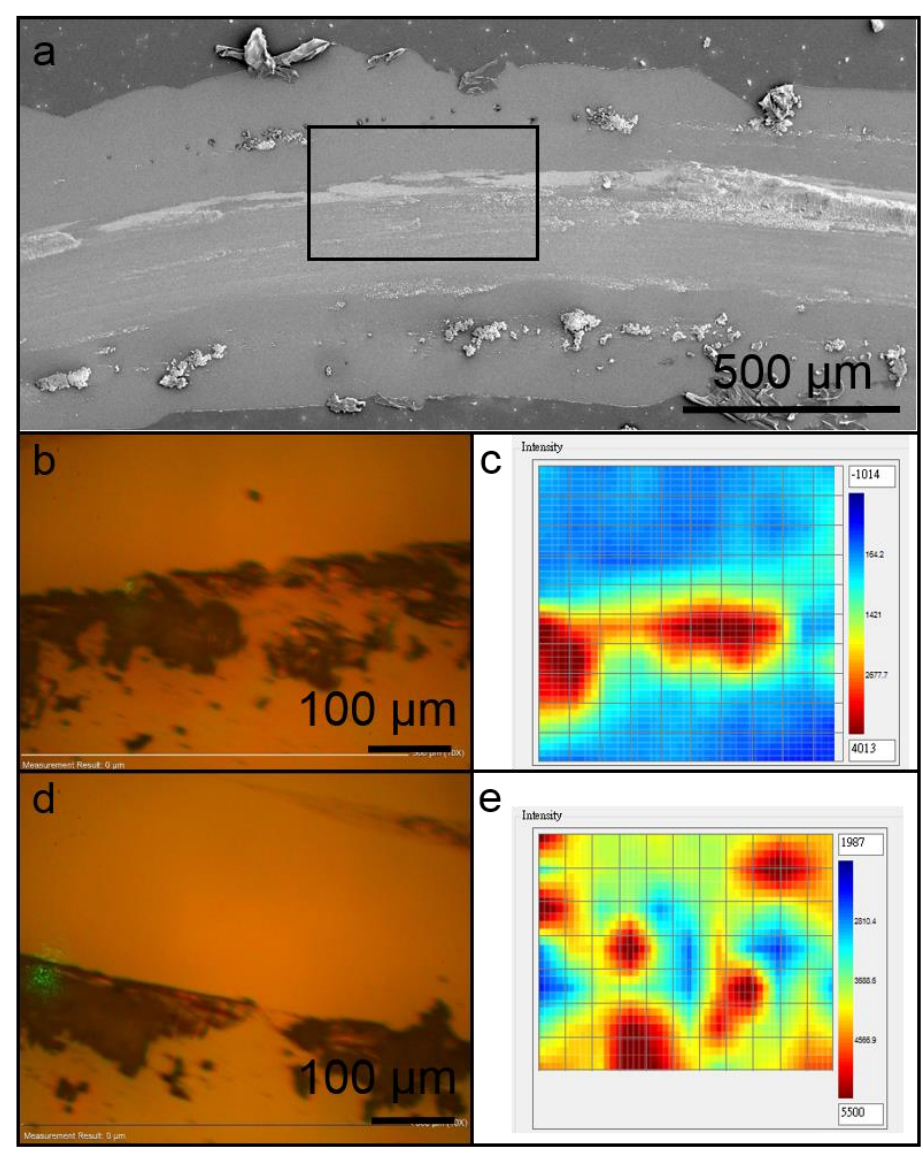

Figure 10. (a) SEM image of the wear track; (b) OM image of wear scar at a wear distance of $10 \mathrm{~m}$; (c) Raman mapping image of (b); (d) OM image of wear scar at a wear distance of $15 \mathrm{~m}$; (e) Raman mapping image of $(\mathbf{d})$.

As per the third-body theory, graphene on the surface of the chrome steel ball represents the velocity accommodation mechanism of S1M3; the residual graphene on the coating surface presents the velocity accommodation mechanism of S5M3. A small amount of nano-graphene/copper additive can effectively form a transfer layer, which is transferred to form third-body layers. The third-body layer between two moving planes offers the wear mechanism of S1M3 and S5M3, which effectively reduces the wear and friction coefficient.

\section{Conclusions}

Large-area spraying technology was developed, and NGCC were prepared on flexible glass substrates. The material properties and wear characteristics of the composite film on the glass substrate show that the prepared coating has good functionality as a solid protective coating. Spraying exhibits an excellent thickness control capability. The surface roughness increases with the increase in additive owing to the particle agglomeration. The natural hydrophobic properties of NGCC help to improve the lubrication. The effective distribution of nano-additives in the matrix is proven by the SEM and Raman mapping. In NGCC $(0.1 \%-0.3 \%)$, at least a $20 \%$ reduction in wear and friction is achieved. Specifically, $0.1 \%$ NGCC can result in $20 \%$ wear reduction, with a $40 \%$ reduction in friction being possible under the optimal conditions. The graphene was found either in the upper specimen (chromium steel ball) or in the wear tracks, indicating that the tribological mechanism is dominated by the transfer layer of graphene. The S1M3 and S5M3 are proposed as the third-body wear mechanisms.

Featured Application: The successful development of a large-area manufacturing process is suitable for applying graphene/ $\mathrm{Cu} / \mathrm{cellulose}$ composite with great protective properties to the protection of large substrates, especially the most common large-size glass substrates. The easy synthesis and 
preparation of the protective layer has advantages in commercial applications. The third-body friction mechanism of nanographene-reinforced cellulose materials has also been proposed.

Author Contributions: Conceptualization, S.-C.S.; methodology, S.-C.S.; formal analysis, S.-C.S.; investigation, S.-C.S.; resources, S.-C.S., C.-C.W., Y.-C.C. and Y.-F.L.; writing-original draft preparation, S.-C.S.; writing-review and editing, S.-C.S.; supervision, S.-C.S.; project administration, S.-C.S.; funding acquisition, S.-C.S. All authors have read and agreed to the published version of the manuscript.

Funding: The authors gratefully acknowledge the financial supports for this project from the Ministry of Science and Technology in Taiwan (MOST 106-2221-E-006-092-MY3 and MOST 109-2221-E-006-046).

Acknowledgments: The authors also thank the National Cheng Kung University Library for the funding support and the Center for Micro/Nano Science and Technology and Instrument Center, National Cheng Kung University (NCKU) for technical support.

Conflicts of Interest: The authors declare no conflict of interest.

\section{References}

1. Zheng, J.; Zhang, M.; Lau, C.F.J.; Deng, X.; Kim, J.; Ma, Q.; Chen, C.; Green, M.A.; Huang, S.; Ho-Baillie, A.W. Spin-coating free fabrication for highly efficient perovskite solar cells. Solar Energy Mater. Solar Cells 2017, 168, 165-171. [CrossRef]

2. Han, G.S.; Kim, J.; Bae, S.; Han, S.; Kim, Y.J.; Gong, O.Y.; Lee, P.; Ko, M.J.; Jung, H.S. Spin-coating process for $10 \mathrm{~cm} \times 10 \mathrm{~cm}$ perovskite solar modules enabled by self-assembly of $\mathrm{SnO}_{2}$ nanocolloids. ACS Energy Lett. 2019, 4, 1845-1851. [CrossRef]

3. Ariyakkani, P.; Suganya, L.; Sundaresan, B. Investigation of the structural, optical and magnetic properties of Fe doped ZnO thin films coated on glass by sol-gel spin coating method. J. Alloys Compd. 2017, 695, 3467-3475. [CrossRef]

4. Khan, M.; Bhatti, K.; Qindeel, R.; Alonizan, N.; Althobaiti, H.S. Characterizations of multilayer ZnO thin films deposited by sol-gel spin coating technique. Results Phys. 2017, 7, 651-655. [CrossRef]

5. Khan, M.; Bhatti, K.; Qindeel, R.; Althobaiti, H.S.; Alonizan, N. Structural, electrical and optical properties of multilayer $\mathrm{TiO}_{2}$ thin films deposited by sol-gel spin coating. Results Phys. 2017, 7, 1437-1439. [CrossRef]

6. Habibi, M.; Rahimzadeh, A.; Bennouna, I.; Eslamian, M. Defect-free large-area $\left(25 \mathrm{~cm}^{2}\right)$ light absorbing perovskite thin films made by spray coating. Coatings 2017, 7, 42. [CrossRef]

7. Chu, H.-C.; Chang, Y.-C.; Lin, Y.; Chang, S.-H.; Chang, W.-C.; Li, G.-A.; Tuan, H.-Y. Spray-deposited large-area copper nanowire transparent conductive electrodes and their uses for touch screen applications. ACS Appl. Mater. Interfaces 2016, 8, 13009-13017. [CrossRef]

8. Zhou, P.; Li, W.; Li, T.; Bu, T.; Liu, X.; Li, J.; He, J.; Chen, R.; Li, K.; Zhao, J. Ultrasonic spray-coating of large-scale $\mathrm{TiO}_{2}$ compact layer for efficient flexible perovskite solar cells. Micromachines 2017, 8, 55. [CrossRef]

9. Zhang, S.; Chen, S.; Hu, F.; Xu, R.; Yan, B.; Jiang, M.; Gu, Y.; Yang, F.; Cao, Y. Spray-processable, large-area, patterned and all-solid-state electrochromic device based on silica/polyaniline nanocomposites. Solar Energy Mater. Solar Cells 2019, 200, 109951. [CrossRef]

10. Hishimone, P.N.; Nagai, H.; Morita, M.; Sakamoto, T.; Sato, M. Highly-conductive and well-adhered Cu thin film fabricated on quartz glass by heat treatment of a precursor film obtained via spray-coating of an aqueous solution involving $\mathrm{Cu}$ (ii) complexes. Coatings 2018, 8, 352. [CrossRef]

11. Nguyen, M.D.; Bang, J.W.; Kim, Y.H.; Bin, A.S.; Hwang, K.H.; Pham, V.-H.; Kwon, W.-T. Slurry spray coating of carbon steel for use in oxidizing and humid environments. Ceram. Int. 2018, 44, 8306-8313. [CrossRef]

12. Rao, R.R.; Dange, E.; Udayakumar, A. Synthesis and slurry spray coating of barium strontium alumino silicate on sic substrate. Ceram. Int. 2020, in press. [CrossRef]

13. Shi, S.-C.; Yang, J.H.C. Preparation of stable biopolymer composite suspension with metal/metal-oxide nanoparticles. Mod. Phys. Lett. B 2020, 34, 2040028. [CrossRef]

14. Shi, S.-C.; Peng, Y.-Q. Preparation and tribological studies of stearic acid-modified biopolymer coating. Prog. Org. Coat. 2020, 138, 105304. [CrossRef]

15. Shi, S.-C.; Tsai, X.-N.; Pek, S.-S. Tribological behavior and energy dissipation of hybrid nanoparticle-reinforced hpmc composites during sliding wear. Surf. Coat. Technol. 2020, 389, 125617. [CrossRef]

16. Shi, S.-C.; Jiang, S.-Z. Influence of graphene/copper hybrid nanoparticle additives on tribological properties of solid cellulose lubricants. Surf. Coat. Technol. 2020, 389, 125655. [CrossRef] 
17. Qin, L.; Feng, X.; Hafezi, M.; Zhang, Y.; Guo, J.; Dong, G.; Qin, Y. Investigating the tribological and biological performance of covalently grafted chitosan coatings on Co-Cr-Mo alloy. Tribol. Int. 2018, 127, $302-312$. [CrossRef]

18. Qin, L.; Sun, H.; Hafezi, M.; Zhang, Y. Polydopamine-assisted immobilization of chitosan brushes on a textured cocrmo alloy to improve its tribology and biocompatibility. Materials 2019, 12, 3014. [CrossRef] [PubMed]

19. Chang, Q.; Zhang, H.; Gao, R. Magnesium silicate hydroxide modified by carbon from hydrothermal carbonization of gelatin for tribological application. Diam. Relat. Mater. 2019, 95, 36-43. [CrossRef]

20. Anvari, M.; Joyner, H.S. Effect of formulation on structure-function relationships of concentrated emulsions: Rheological, tribological, and microstructural characterization. Food Hydrocoll. 2017, 72, 11-26. [CrossRef]

21. Shi, S.-C.; Su, C.-C. Electrochemical behavior of hydroxypropyl methylcellulose acetate succinate as novel biopolymeric anticorrosion coating. Mater. Chem. Phys. 2020, 248, 122929. [CrossRef]

22. Shi, S.-C. Electrochemical properties of biopolymers in strong acid and application in displacement sensor. Sens. Mater. 2019, 31, 1599-1608. [CrossRef]

23. Biswas, A.; Das, D.; Lgaz, H.; Pal, S.; Nair, U.G. Biopolymer dextrin and poly (vinyl acetate) based graft copolymer as an efficient corrosion inhibitor for mild steel in hydrochloric acid: Electrochemical, surface morphological and theoretical studies. J. Mol. Liq. 2019, 275, 867-878. [CrossRef]

24. Shi, S.-C.; Su, C.-C. Corrosion inhibition of high speed steel by biopolymer hpmc derivatives. Materials 2016, 9, 612. [CrossRef] [PubMed]

25. Shi, S.-C.; Huang, T.-F. Effects of temperature and humidity on self-healing behaviour of biopolymer hydroxylpropyl methylcellulose for ecotribology. Surf. Coat. Technol. 2018, 350, 997-1002. [CrossRef]

26. Wang, C.; Liang, C.; Wang, R.; Yao, X.; Guo, P.; Yuan, W.; Liu, Y.; Song, Y.; Li, Z.; Xie, X. The fabrication of a highly efficient self-healing hydrogel from natural biopolymers loaded with exosomes for the synergistic promotion of severe wound healing. Biomater. Sci. 2020, 8, 313-324. [CrossRef]

27. Shi, S.-C.; Huang, T.-F. Self-healing materials for ecotribology. Materials 2017, 10, 91. [CrossRef]

28. Shi, S.-C.; Wu, J.-Y.; Peng, Y.-Q. Transfer layer formation in $\mathrm{MoS}_{2}$ /hydroxypropyl methylcellulose composite. Wear 2018, 408, 208-213. [CrossRef]

29. Shi, S.-C.; Wu, J.-Y. Deagglomeration and tribological properties of $\mathrm{MoS}_{2} /$ hydroxypropyl methylcellulose composite thin film. Surf. Coat. Technol. 2018, 350, 1045-1049. [CrossRef]

30. Shi, S.-C. Tribological performance of green lubricant enhanced by sulfidation if-MoS 2 . Materials 2016, 9, 856. [CrossRef]

31. Shi, S.-C.; Wu, J.-Y.; Huang, T.-F.; Peng, Y.-Q. Improving the tribological performance of biopolymer coating with $\mathrm{MoS}_{2}$ additive. Surf. Coat. Technol. 2016, 303, 250-255. [CrossRef]

32. Reeves, C.J.; Menezes, P.L.; Lovell, M.R.; Jen, T.-C. The influence of surface roughness and particulate size on the tribological performance of bio-based multi-functional hybrid lubricants. Tribol. Int. 2015, 88, 40-55. [CrossRef]

33. Shi, S.-C.; Chen, T.-H.; Mandal, P.K. Enhancing the mechanical and tribological properties of cellulose nanocomposites with aluminum nanoadditives. Polymers 2020, 12, 1246. [CrossRef] [PubMed]

34. Sankar, K.V.; Selvan, R.K.; Vignesh, R.H.; Lee, Y. Nitrogen-doped reduced graphene oxide and aniline based redox additive electrolyte for a flexible supercapacitor. RSC Adv. 2016, 6, 67898-67909. [CrossRef]

35. Lewis, J.S.; Barani, Z.; Magana, A.S.; Kargar, F.; Balandin, A.A. Thermal and electrical conductivity control in hybrid composites with graphene and boron nitride fillers. Mater. Res. Express 2019, 6, 085325. [CrossRef]

36. Afrand, M. Experimental study on thermal conductivity of ethylene glycol containing hybrid nano-additives and development of a new correlation. Appl. Therm. Eng. 2017, 110, 1111-1119. [CrossRef]

37. Tang, Y.; Su, D.; Huang, X.; Alva, G.; Liu, L.; Fang, G. Synthesis and thermal properties of the ma/hdpe composites with nano-additives as form-stable pcm with improved thermal conductivity. Appl. Energy 2016, 180, 116-129. [CrossRef]

38. Wang, X.; Huang, Y.; Wu, G.; Fang, C.; Li, D.; Han, N.; Xing, F. Effect of nano-SiO 2 on strength, shrinkage and cracking sensitivity of lightweight aggregate concrete. Constr. Build. Mater. 2018, 175, 115-125. [CrossRef]

39. Cho, Y.-K.; Yoo, S.-W.; Jung, S.-H.; Lee, K.-M.; Kwon, S.-J. Effect of $\mathrm{Na}_{2} \mathrm{O}$ content, $\mathrm{SiO}_{2} / \mathrm{Na}_{2} \mathrm{O}$ molar ratio, and curing conditions on the compressive strength of Fa-based geopolymer. Constr. Build. Mater. 2017, 145, 253-260. [CrossRef]

40. Godet, M. Third-bodies in tribology. Wear 1990, 136, 29-45. [CrossRef] 
41. Godet, M. The third-body approach: A mechanical view of wear. Wear 1984, 100, 437-452. [CrossRef]

42. Shi, S.-C.; Pek, S.-S. Third-body and dissipation energy in green tribology film. Appl. Sci. 2019, 9, 3787. [CrossRef]

43. Fahs, A.; Brogly, M.; Bistac, S.; Schmitt, M. Hydroxypropyl methylcellulose (hpmc) formulated films: Relevance to adhesion and friction surface properties. Carbohydr. Polym. 2010, 80, 105-114. [CrossRef]

Publisher's Note: MDPI stays neutral with regard to jurisdictional claims in published maps and institutional affiliations.

(C) 2020 by the authors. Licensee MDPI, Basel, Switzerland. This article is an open access article distributed under the terms and conditions of the Creative Commons Attribution (CC BY) license (http://creativecommons.org/licenses/by/4.0/). 